\title{
A Novel Approach in Identification of Urban Hot Spot Using Geospatial Technology: A Case Study in Kamrup Metro District of Assam
}

\author{
Jonali Goswami, Shreya Roy, S. Sudhakar \\ Department of Space, North Eastern Space Applications Centre, Umiam, India \\ Email: Jonali.goswami@gmail.com,hi_rumpa@yahoo.co.in,s.sudhakar@nesac.gov.in
}

Received April 19, 2013; revised May 22, 2013; accepted June 20, 2013

Copyright (C) 2013 Jonali Goswami et al. This is an open access article distributed under the Creative Commons Attribution License, which permits unrestricted use, distribution, and reproduction in any medium, provided the original work is properly cited.

\begin{abstract}
Urbanization in recent years plays an important role in increase in impervious areas with reducing in vegetation cover and pervious areas of natural landscape. This leads to a rise in temperature of urban areas, by several degrees particularly at night $[1,2]$. A novel geospatial approach has been adopted to determine the maximum temperature areas (hot spots) over Kamrup Metro District of Assam, which is a gateway for seven neighboring north eastern states of India. The G statistics have been calculated for detecting the presence of hot spot or cold spot over the entire study area which is a new approach in urban heat island studies. The resultant z-scores and p-values show the pixels with either high or low values cluster spatially. For statistically significant positive z-scores, the larger the z-score is, the more intense the clustering of high values (hot spot) and vice versa. Land Surface Temperature (LST) anomaly values and percentage of Impervious Surface Area (ISA) along with climatic data are used to conform the hot spot location. It is one of the densely populated areas with more commercial pockets thereby giving rise to anthropogenic heat discharge which accelerates the heat island phenomenon. Incorporation of socio-economic survey data as well as certain biophysical parameters can be used to know about the cause and future impact of urbanization.
\end{abstract}

Keywords: Hot Spot; LST; G Statistics; Impervious Area; Geospatial; RS GIS

\section{Introduction}

Vegetation cover has been replaced by impervious areas in most parts of the world in recent years thus giving rise to urban heat island, in which the temperature of urban areas is several degrees higher than non urbanized areas surrounding them, particularly at night $[1,2]$. The impervious areas is largely contributed by use of materials like concrete, bricks, tiles etc. for buildings and bitumen for roads and parking lots [3]. The introduction of new surface materials coupled with emission of heat, moisture and pollutants dramatically change radiative, thermal, moisture, roughness and emission properties of the surface and the atmosphere above [4]. The effect of this can be analyzed by observing the variation of night time LST over different land use classes within the study area. LST is generally defined as the skin temperature of the surface which refers to land temperature for bare soil, canopy surface temperature for densely vegetated ground and combination of two in case of sparsely vegetated ground. Satellite derived LST has been used for a number of urban hot spot analysis where LST dynamics with bio- physical properties has been studied [5-7]. Past studies explain the fact that green areas provide a cooling effect to the surroundings in a city and the increase in building spaces leads to a rise in LST.

Another indicator of urban hot spot is the percent impervious area (\%ISA) which bears a strong linear relationship with the LST [8]. The amount of impervious surfaces is related to population growth and urbanization [3]. The first global grid of \%ISA at one $\mathrm{km}$ grid has been prepared by Earth Observation Group, NOAA National Geophysical Data Center, based on two coarse resolution indicators of ISA - the brightness of satellite observed nighttime lights and population count.

The main objective of this study is to determine the maximum temperature areas (hot spots) over Kamrup Metro District of Assam using MODIS night time LST, $\%$ ISA along with climatic data for the month of May.

\section{Study Area}

Kamrup Metropolitan District is the capital of Assam 
state, located in north eastern region of India with a geographical area of $127.84 \mathrm{sq} \mathrm{km}$ (Figure 1). The total population as per Census 2001 is 1,062,771 with urban population 850,136 nos and rural population 216,635 nos with population density of 836 per sq $\mathrm{km}$ [9]. Built up area has increased from 111 square kilometer to 131 square kilometer (horizontal expansion) during last ten years (Figure 2) with substantial vertical expansion over the years.

\section{Materials and Methods}

\subsection{Data Used}

1) Eight days land surface temperatures and emissivity product of MODIS onboard Terra, MOD11A2, which come with a spatial resolution of $1 \mathrm{~km}$, were used in this study. Ten years data (2000-2012) for the Julian day 137 (May 17). They are arranged in 10 degree by 10 degree in sinusoidal grid.

2) Global grid of \%ISA data product at $1 \mathrm{~km}$ resolution [10].

3) High Resolution Worldview PAN mosaic data (08-09) of Guwahati Metropolitan Area of Kamrup Metro district which comes at a spatial resolution of $0.46 \mathrm{~m}$.

4) Land Use Land Cover (LULC) map of Kamrup Metro district were extracted from LULC $250 \mathrm{~K}$ of As-

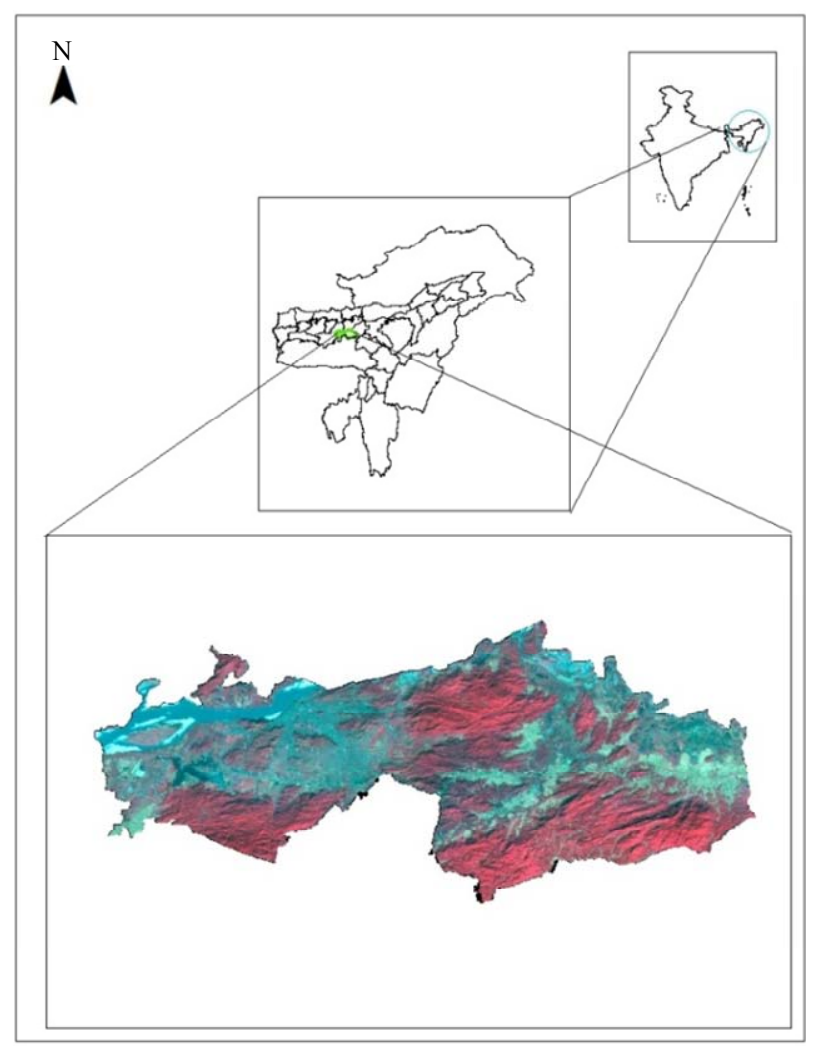

Figure 1. Location of study area. sam prepared under LULC $250 \mathrm{~K}$ Project, NRSC, ISRO.

5) Meteorological data: $1^{\circ} \times 1^{\circ}$ gridded temperature data (1980-2005), $1 / 2^{\circ} \times 1 / 2^{\circ}$ rainfall data (1980-2011), Normal mean monthly rainfall and temperature for Kamrup district (Metro and Rural district) from IMD and ISRO Automatic Weather Station (AWS) data from MOSDAC website.

6) Other ancillary data include: Boundary of Kamrup Metro and Guwahati Metropolitan Area, Building inventory.

\subsection{Methodology}

Land use of Kamrup metro was extracted from 9th cycle (2011-2012) LULC $250 \mathrm{~K}$ database of Assam to get broad classes like Forest, Agriculture, Grassland, Wastelands, Wetland, Water bodies, Tree Clad areas etc. However, different built up categories were extracted from LULC $50 \mathrm{~K}$. High resolution data of Worldview Pan has been used to visualize the urban built up density within the hot spot area. MODIS data sets re-projected in the Universal Transverse Mercator with WGS/84 datum and re-sampled to $250 \mathrm{~m}$. MODIS night time LSTs products available during 2000 to 2012 were used and converted to degree centigrade. Julian day of 137 for the year 2003, 2009, 2011, 2012 was found to be cloud free for the entire study area and was used for further analysis. Mean LST for last three years $(2009,2011$, and 2012) were computed and difference in LST value (LST anomaly) was determined from the year 2003 to computed mean. Positive values indicate increase in temperature. LST distribution over different land use classes of the district was then extracted to get distribution pattern of LST over different land use classes. A novel approach has been adopted to detect the presence of hot spot or cold spot over the entire study area by calculating $G$ statistics [11] for each feature (pixel) in a dataset as shown in Equations (1)-(3). The resultant $G_{i}^{*}$ (z-scores and p-values) shows where the pixels with either high or low values cluster spatially. A feature or pixel with a high value may not be a statistically significant hot spot. To be a statistically significant hot spot, a feature will have a high value and be surrounded by other features with high values as well. The local sum for a feature and its neighbors is compared proportionally to the sum of all features; when the local sum is very different from the expected local sum, and that difference is too large to be the result of random chance, a statistically significant z-score result. For statistically significant positive $\mathrm{z}$-scores, the larger the $z$-score is, the more intense the clustering of high values (hot spot). For statistically significant negative $\mathrm{z}$-scores, the smaller the $\mathrm{z}$-score is, the more intense the clustering of low values (cold spot). 


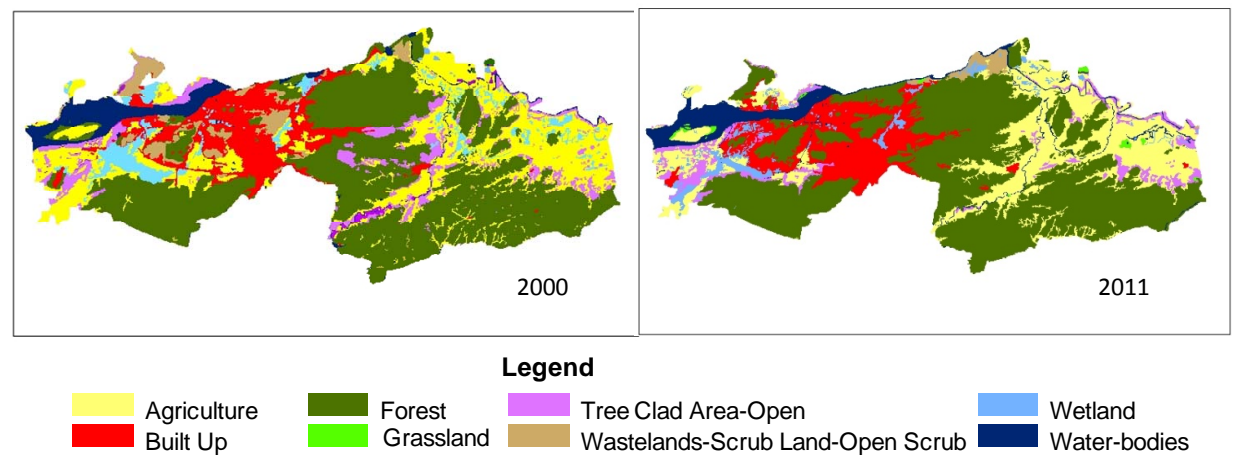

Figure 2. Land use and land cover change in the year 2000 and 2011.

$$
\begin{gathered}
G_{i}^{*}=\frac{\sum_{j=1}^{n} w_{i, j} x_{j}-\bar{X} \sum_{j=1}^{n} w_{i, j}}{\sqrt{\frac{\left[n \sum_{j=1}^{n} w_{i, j}^{2}-\left(\sum_{j=1}^{n} w_{i, j}\right)^{2}\right]}{n-1}}} \\
\bar{X}=\frac{\sum_{j=1}^{n} x_{j}}{n} \\
S=\sqrt{\frac{n \sum_{j=1}^{n} x_{j}^{2}}{n}-(\bar{X})^{2}}
\end{gathered}
$$

where $G_{i}^{*}$ is the resultant $G$ statistics (z-scores and pvalues) for pixel $i, x_{j}$ is the LST value for pixel $j, w_{i, j}$ is the spatial weight between pixel $i$ and neighboring pixel $j$, $n$ is equal to the total number of pixels, $\bar{X}$ and $S$ are mean and variance.

The output was then reclassified based on the $G_{i}^{*}(\mathrm{z}$ score) value associated with probability value and made into seven classes as given in Table 1. Statistically, significant positive $\mathrm{z}$-scores i.e. the larger value of $\mathrm{z}$-score means the more intense the clustering of high values (hot spot).

Hence, Class 7 was considered as the desired hot spot with highest $\mathrm{z}$ score value associated with small $\mathrm{p}$ value (0.01) at $99 \%$ confidence level. Further land use classes are extracted to observe the distribution of different land use categories in hot spot areas.

LST anomaly values and percentage of Impervious Surface Area (ISA) are used to conform the location as $\%$ ISA can be used as a complementary metric to the traditionally applied Normalized Difference Vegetation Index for analyzing LST quantitatively over the seasons for surface urban heat island studies [8]. Global \%ISA $1 \mathrm{~km}$ grid are imported from "tiff" to "img", and \%ISA over Kamrup metro are clipped and its distribution over various land uses of Kamrup metro are analyzed.

Historical data of rainfall and temperature over Kamrup was also analysed to understand the trend over the years. Apart from that two ground based automatic weather stations (AWS) located one within the hot pixels
Table 1. Classification based on $\mathrm{p}$ value and $\mathrm{z}$ score.

\begin{tabular}{ccc}
\hline $\begin{array}{c}\text { Significance Level } \\
(\mathrm{p} \text { Value })\end{array}$ & $\begin{array}{c}\text { Critical Value } \\
(\mathrm{z} \text { Score })\end{array}$ & Class No. \\
\hline-0.01 & $<-2.58$ & Class 1 \\
-0.05 & $-2.58--1.96$ & Class 2 \\
-0.10 & $-1.96--1.65$ & Class 3 \\
0 & $-1.65-1.65$ & Class 4 \\
0.10 & $1.65-1.96$ & Class 5 \\
0.05 & $1.96-2.58$ & Class 6 \\
0.01 & $>2.58$ & Class 7 \\
\hline
\end{tabular}

(91 46'23.99"E, 26 $\left.{ }^{\circ} 9^{\prime} 41^{\prime \prime N}\right)$ at Assam Science and Technology Centre (ASTEC) and another outside at Kahikuchi $\left(91^{\circ} 42^{\prime} 59^{\prime \prime} \mathrm{E}, 26^{\circ} 10^{\prime} 44^{\prime \prime} \mathrm{N}\right)$ was selected to study the impact of UHI on climatic parameters.

\section{Results \& Discussions}

LST distribution over different land use classes were observed using last five years mean for the month of May. Built up areas shows the highest night LST (Figure 3) followed by agricultural field.

A feature or pixel with a high value of LST may not be a statistically significant hot spot. Area falls under class 7 with statistically significant positive z-scores $(>2.58)$ is observed to be hot spot at $99 \%$ confidence level as shown in Figure 4. Dominant land use in observed in hot spot area (Class 7) is built up. About $84 \%$ area covers with mixed built up under that particular class. On the other hand mixed built up area shows more impact on hot spot of the study area.

It has also observed high percentage of Impervious Surface Area (ISA) over hot spot location (Figure 5). LST and ISA shows high positive correlation $\left(\mathbf{R}^{2}=\mathbf{0 . 5 9}\right)$ over the study area. Highest LST and ISA exhibits by built up area. Figure 6 shows the variation of LST and ISA over various land uses of the study area. 


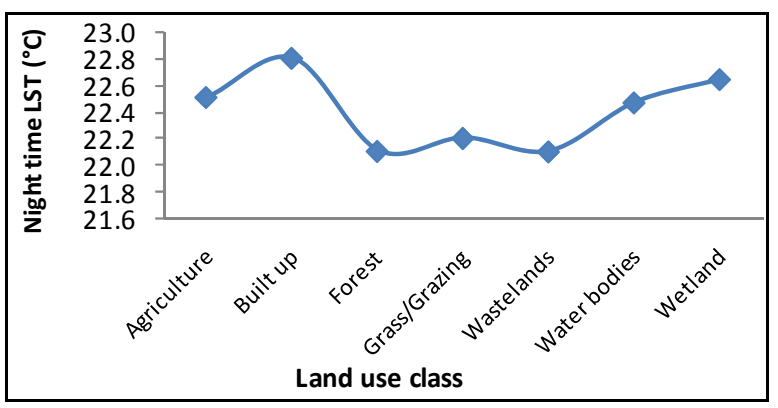

Figure 3. Distribution of LST over different land use classes.
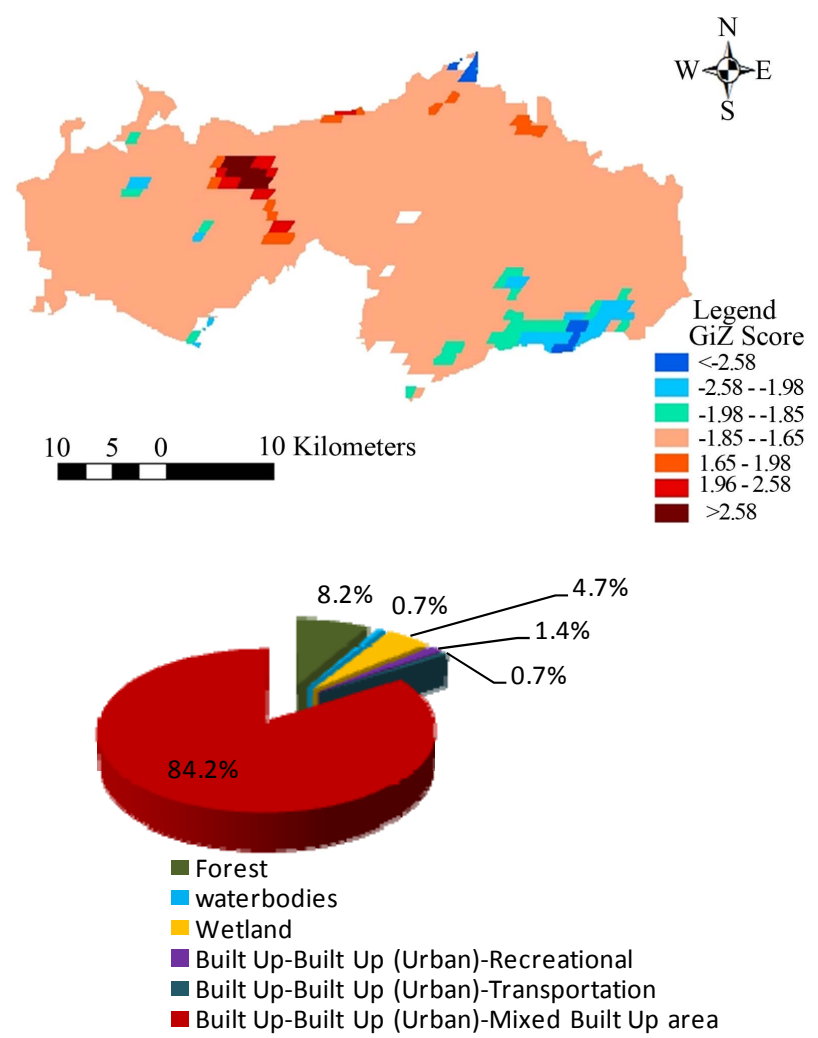

Figure 4. Spatial location of hot spot and land covers distribution (percent area) in hot spot area.

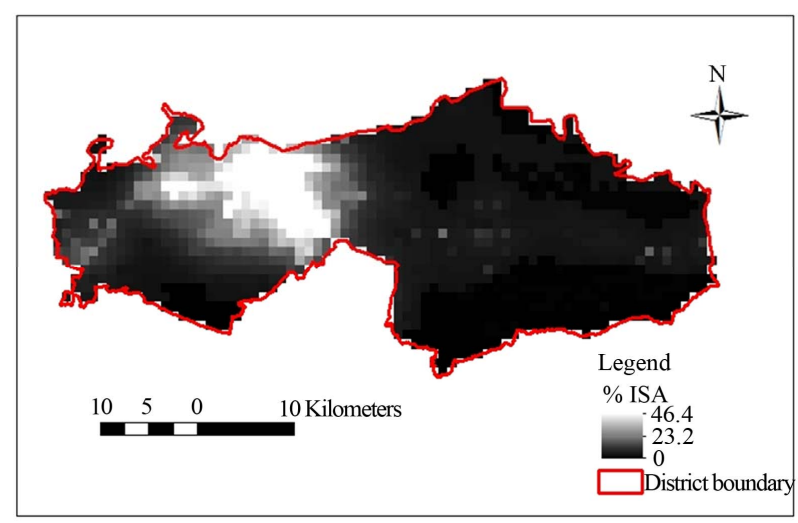

Figure 5. Spatial view of percentage ISA.
LST anomaly has been worked out using cloud free data of same period of the year 2003. Highest anomaly is also observed in and around hot spot areas (Figure 7). Maximum anomaly observed mainly in built up area followed by tree clad area, which mostly includes small huts with homestead garden and agricultural field particularly current fallow land.

While the surface urban hot spot is typically characterized as land surface temperature (LST), atmospheric urban hot spot are normally measured by in situ sensors of air temperature via weather station networks [8]. It has been observed (Figure 8) that over the last decade there is an increasing trend in maximum temperature from May to October over Kamrup (Metro and Rural district) as compared to normal from 1971-2000. Similarly there is a decreasing trend in rainfall pattern as compared to last two decades particularly from May-September. Pre and post monsoon has also shown decreasing trend as shown in Figure 9. Pre monsoon and post monsoon also shows an inverse relation over the years.

Similarly analysis has been done to see the temperature and rainfall variation over Kamrup district particularly in the month of May (Figure 10). It has been observed that there is an increasing trend of maximum temperature with decrease in rainfall activity from 1995 onwards. Figure 11 also shows that there is an increase in

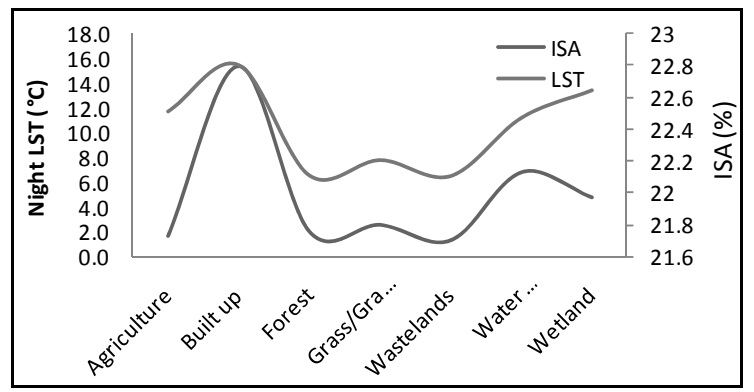

Figure 6. Variation of LST and ISA over various land use classes.

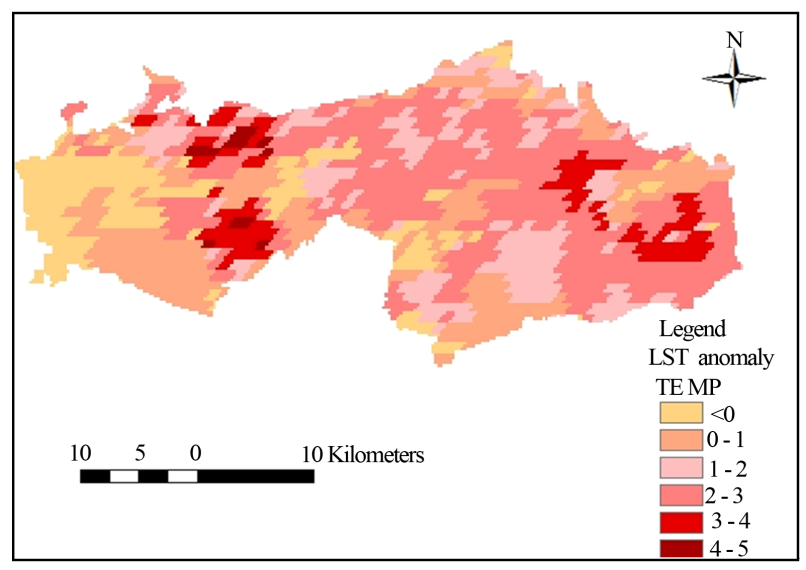

Figure 7. LST anomaly for a period of 10 years. (Positive anomaly indicates increase in temperature.) 

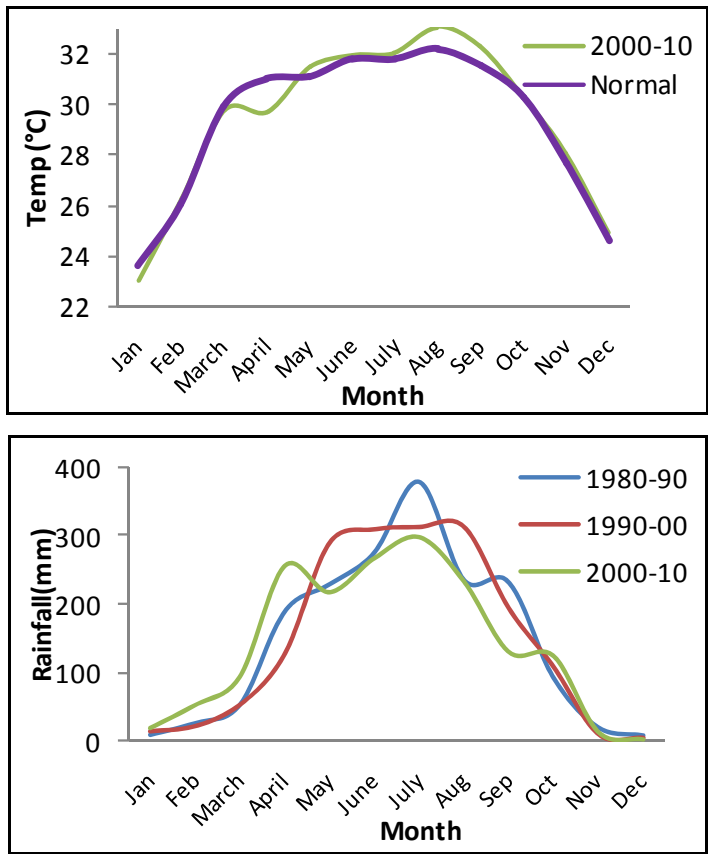

Figure 8. Monthly decadal temperature and rainfall distribution over Kamrup.

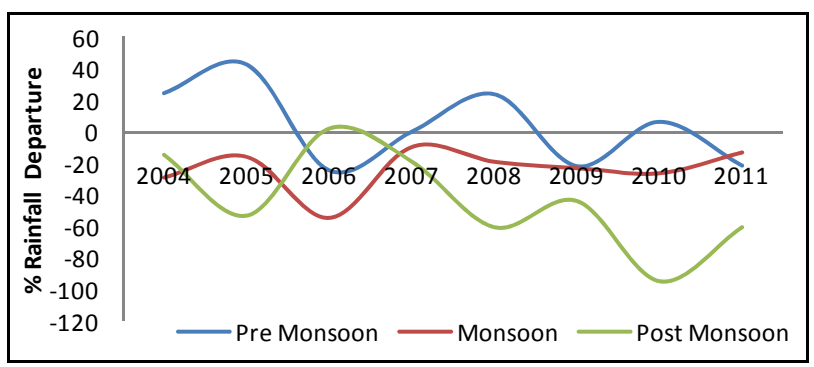

Figure 9. Pre, post and monsoonal rainfall departure over Kamrup for last eight years

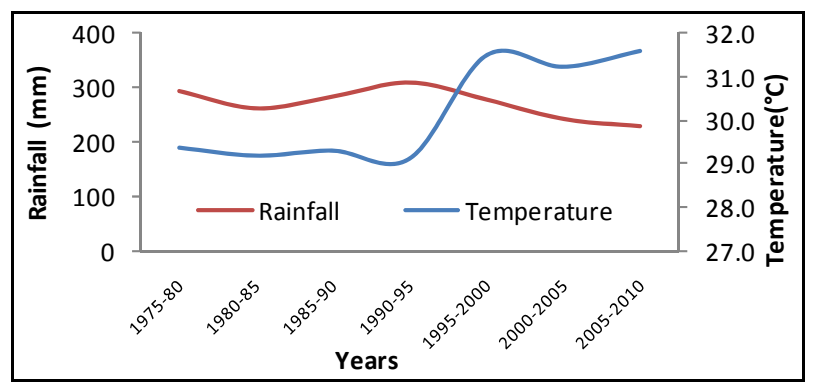

Figure 10. Rainfall and temperature variation for the month of May over Kamrup.

maximum temperature with decrease in rainfall activity within the hot pixel area.

In the study district, hot spot have been identified in the areas of the densely populated area with more commercial pockets thereby giving rise to anthropogenic heat discharge which accelerates the heat island phenomenon. The location of the urban hot spot shows both rise in
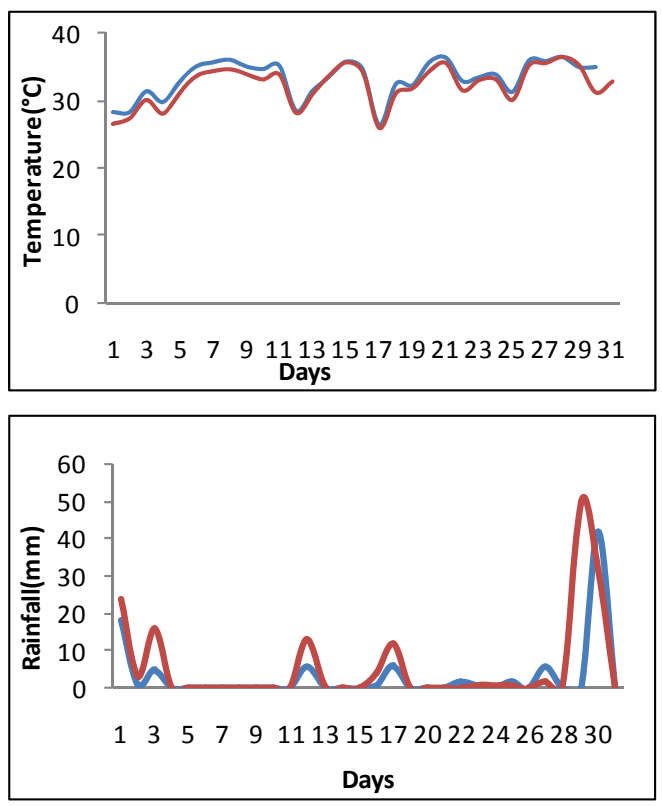

Figure 11. Temperature and rainfall variation over hot pixel area (ASTEC) and outside the hot pixel area (Kahikuchi) for the month of May, 2012.

surface and atmospheric temperature.

\section{Conclusion}

This study investigates the use of G statistics in determining the unusual pattern of spatial association which is significantly different to what is generally observed across the whole study area. Results indicate \%ISA is an important indicator of rise in surface temperature with positive linear relationship between LST. Vegetation cover provides a cooling effect to the surroundings. Thus, in the future city planning and development more attention should be paid to urban greening and a minimum available space between the buildings. A new concept of urban farming is also in the picture now a day. However, the shortcoming in this case study is unavailability of cloud free satellite data for other seasons as well. There is also a lack of a good network of ground based observation on climatic parameters. This study can be attempted with high resolution satellite data and other socio-economic survey data to know about the cause and future impact of urban heat island.

\section{REFERENCES}

[1] D. R. Streutker, "A Remote Sensing Study of the Urban Heat Island of Houston, Texas," International Journal of Remote Sensing, Vol. 23, No. 13, 2002, pp. 2595-2608. doi:10.1080/01431160110115023

[2] J. A. Voogt and T. R. Oke, "Thermal Remote Sensing of Urban Climates," Remote Sensing of Environment, Vol. 86, No. 3, 2003, pp. 370-384. 
doi:10.1016/S0034-4257(03)00079-8

[3] S. J. Stanwoski, "Population Density as an Indirect Indicator of Urban and Sub-Urban Land Surface Modifications," US Geological Survey, pp. B219-B224.

[4] M. Roth, "Effects of Cities on Local Climates," Proceedings of Workshop of Institute for Global Environment Studies/Asia-Pacific Network (IGES/APN), Kitakyushu, 23-25 January, p. 13.

[5] B. R. Parida, B. Oinam, N. R. Patel, N. Sharma, R. Kandwal and M. K. Hazarika, "Land Surface Temperature VaRiation in Relation to Vegetation Type Using MODIS Satellite Data in Gujarat State of India," International Journal of Remote Sensing, Vol. 29, No. 14, 2008, pp. 4219-4235. doi:10.1080/01431160701871096

[6] S. Dumitrescu and S. Cheval, "The July Urban Heat Island of Bucharest as Derived from MODIS Images," Theoretical and Applied Climatology, Vol. 96, No. 1-2, 2009, pp. 145-153.
[7] S. Khandelwal, R. Goyal, N. Kaul and V. Singhal, "Study of Land Surface Temperature Variations with Distance from Hot Spots for Urban Heat Island Analysis," Geospatial World Forum, Theme Dimensions and Directions of Geospatial Industry, 18-21 January 2011, Hyderabad.

[8] F. Yuan and M. E. Baur, "Comparison of Impervious Surface Area and Normalized Difference Vegetation Index as Indicators of Surface Urban Heat Island Effects in Landsat Imagery," Remote Sensing of Environment, Vol. 106, No. 3, 2007, pp. 375-386. doi:10.1016/j.rse.2006.09.003

[9] District at a Glance. http://kamrupmetro.nic.in/glance.asp

[10] Global Distribution and Density of Constructed Impervious Surfaces. http://ngdc.noaa.gov/eog/dmsp/download_global_isa.html

[11] A. Getis and J. K. Ord, "The Analysis of Spatial Association by Use of Distance Statistics," Geographical Analysis, Vol. 24, No. 3, 1992, pp. 189-207. doi:10.1111/j.1538-4632.1992.tb00261.x 